This symposium, held in Milan on August 31 and September 1, 1953, under the auspices of the Italian Rheumatological Society and the University of Milan, was attended by many European physicians.

The congress was excellently organized under the presidency of Prof. L. Villa (Milan), and sufficient time was left in each session for diseussion of the papers and replies by those presenting them. The simultaneous translation into three languages was of a very high order.

Biology.-Prof. A. C. DA Costa (Lisbon) reviewed recent work on the development and histology of the suprarenal cortex.

Prof. C. Cavallero (Milan) reported work from his laboratory confirming the increased mortality from tubercular infection in animals treated with cortisone, and showing that the death rate from pneumococci is also raised in animals when the hormone is exhibited. Experimental work with mycoses and cortisone had shown an increase of inflammatory reaction in the skin, but no proliferation of the fungus. No evidence had been found that non-pathogenic organisms became pathogenic under the influence of the drug.

Mr. M. P. Stack-Dunne (Cambridge) discussed the various fractions in ACTH and the tests used to differentiate them.

Dr. C. L. Pirani (Chicago) outlined the association between ascorbic acid and the adrenal cortex; he found $5 \mathrm{~g}$. ascorbic acid in normal men of which 1 per cent. was in the zona reticularis of the cortex. In stress this substance is utilized by the pituitary, and in moderate degrees of stress as much as $300 \mathrm{mg}$. is used daily. Under normal conditions man is supplied with stores of ascorbic acid which are more than adequate to cope with this metabolic need, but administration of the substance was indicated in severe chronic stress.

Prof. P. Leroy (Paris) studied the effect of high doses of cortisone on the testicles of rats. He found that in immature animals there was atrophy of this gland with the hormone, but no change was found in adult rats; studies of spermatozoa showed increased numbers under the influence of cortisone.

Metabolism.-Drs R. LufT and B. SJögren (Stockholm) reported metabolic studies with cortisone, DCA and ACTH over long periods. All these substances caused a retention of sodium chloride, although with continued administration spontaneous excretion of the substances often occurred. Evidence was presented which showed that cortisone gave rise to a deficit of intracellular $\stackrel{\mathbb{Q}}{\varrho}$ potassium, probably resulting from a breakdown of protoplasm. The authors discussed the possibility of a mobilization of sodium from some store in the body, $\vec{\circ}$ presumably bone-tissue. When patients were given a low $\vec{\overrightarrow{ }}$ salt diet there was no significant change in the metabolism $\vec{\omega}$ of sodium chloride, and no significant change in the inulin space with either DCA, cortisone, or ACTH.

Prof. G. Bossa (Naples) described the process of $\vec{N}$ chemical change in the glycoids.

Drs F. Delbarre and F. Coste (Paris) pointed out the importance of discovering whether an endocrine dys-O function played a part in inflammatory arthritis and gave results of their study of metabolic end-products in these $\vec{\omega}$ conditions. They had found the usual methods of estima- $\mathbb{D}$ tion unsatisfactory, and had evolved a procedure based $\frac{\Phi}{\mathbb{D}}$ on the colour reaction of phenyl-hydrazine to concen- $\frac{D}{3}$ trated sulphur. The excretion of corticoids in inflammatory arthritis was within normal limits. Administration of ACTH caused an increase of 30 per cent. \$ृ $\overrightarrow{0}$ normal subjects, but of only 9 per cent. in arthriti\&. Other steroids such as progesterone and pregnenoloni and salicylates and butazolidin caused no increase.

Dr. G. Sala (Milan) discussed the influence of cortisone on the distribution of body fluids and on renal function.

Profs T. LuCHerini and E. CeCCHI (Rome) described the $\stackrel{\unrhd}{\unrhd}$ relationship between cortisone and the somatotrophic $\vec{F}$ hormones, and their antagonistic and synergistic effects in experimental animals and in man.

Profs E. Martin and G. Majno (Geneva) discussed the action of cortisone on bone. Studies had been performed with mice, in which œstradiol benzoate is known to cause an intense osteogenesis. When this was combined with cortisone the reaction was reduced in intensity but not 3 inhibited; osteoblasts produced under the stimulus of oestrogen did not produce normal bone, as if cortisone $\frac{0}{3}$ had inhibited their secretion without hindering their proliferation. Possibly cortisone prevented the synthesis of two fundamental bone components, chondroitin $D$ sulphuric acid and a muco-polysaccharide. This action might be specific in mice and is at present only valid $\overline{\mathrm{N}}$ in this animal.

Clinical Effects.-Drs O. SAvage and W. S. C. COPE- N MAN (London) reported the results of long-term trials of $\mathrm{W}$ cortisone in rheumatoid arthritis. They had experienced many minor side-effects, but few major ones, and weree impressed with the importance of low dosage main- $\overline{\mathbb{D}}$ tenance if treatment were to be practicable. The results $\stackrel{\infty}{+}$ had been encouraging, for patients previously crippled $\square$ 
were able to return to work, but they had been unable to stop administration of the drug save in exceptional cases, and there was no evidence that the course of the disease was altered by cortisone.

Prof. C. B. Ballabio (Milan) spoke on the treatment with cortisone of a type of heart disease which he called "viscerocarditis".

DR. K. BRøCKNER-Mortensen (Copenhagen) reported a similar long-term study in fifty patients with rheumatoid arthritis. Treatment had had to be discontinued in ten, half for unsatisfactory response, three for psychic disturbances, and two for peptic ulcer. Four of the remaining forty went into remission and 36 were still continuing the trial. Only three were able to work before the trial, but this number was increased to 29 during therapy, and the number of totally disabled was reduced from nine to one. He concluded that cortisone is of practical value in selected cases.

Drs R. Scalabrino and M. Rossanda (Milan) stated that cortisone was the treatment of choice in rheumatic carditis.
Drs I. Galli and A. Marmont (Genoa) spoke on the scope of treatment of disseminated lupus erythematosus with cortisone and ACTH.

Drs A. Lunedi, G. Guisti, and G. A. Morandi (Florence) presented a report on cortisone and bleeding, with special reference to the behaviour of the small vessels.

Drs J. Roskam and H. VAN Cauwemberge (Liége) produced evidence in support of the theory that the salicylates act through the increased secretion of ACTH brought about by hypothalamic stimulation.

DR. A. RoBecchI (Turin) reported encouraging results from the use of intra-articular hydrocortisone.

Prof. F. Ceresa (Turin) reported that a breakdown in the functioning of the surrenal cortex had been seen in some cases during ACTH therapy.

Prof. E. Trabucchi (Milan) discussed the nature of the chemical reactions set in motion by steroid therapy.

\section{AN INVESTIGATION OF PHYSICAL TREATMENT AT THE BRITISH SPAS}

At the suggestion and under the direction of the Medical Committee of the British Spas Federation, an investigation of the effect of physical treatment, including hydrotherapy, on rheumatic cases has been carried out at a number of centres.

It was realized from the start that a completely controlled therapeutic trial was impracticable because it was impossible to rule out psychological influences. Such factors must, however, play their part in the effect of therapy, and every effort has been made to give genuine clinical assessments. Only typical cases of rheumatoid arthritis, osteo-arthritis, and fibrositis were investigated, and no parenteral therapy was used during the period of observation. Cases were assessed before treatment, directly (i.e. in 3 to 6 weeks) after treatment, and 3 months later.

Altogether 128 cases of rheumatoid arthritis, 227 of osteo-arthritis, and 112 of fibrositis were followed up in this way, and the results were statistically analysed by E. Lewis-Faning, D.Sc., of the Welsh National School of Medicine. Age, sex, degree of pain on movement or at rest, swelling, tenderness, and range of movement were numerically recorded on a special pro forma. No points of interest were forthcoming from an analysis by age and sex, but a study of the general effect of treatment, both immediate and after 3 months, gave important results which accorded well with clinical impressions.

Approximately half of the 128 patients in the rheumatoid arthritis group appeared to derive significant immediate benefit, and a slightly larger number were found to be definitely improved on a 3 months' review. This applied both to the more "active" and to the more "quiescent" sub-groups. In the former, 68 per cent. showed decreased tenderness and 54 per cent. showed decreased swelling of the worst affected joint, but only 36 per cent. reported a reduction of pain at rest. One patient only appeared to be worse.

In the group of 227 patients with osteo-arthritis, approximately two-thirds stated that they had less pain, and half had increase in range of movement. After 3 months the result was slightly less good, only 62 per cent. stating that they had less pain than before treatment.

In the group of 112 patients with "fibrositis", two-thirds claimed improvement, and 3 months later there was no change in this figure. 